\title{
Debris cover and surface melt at a temperate maritime alpine glacier: Franz Josef Glacier, New Zealand
}

\author{
Martin S. Brook*, Wilfried Hagg** and Stefan Winkler*** \\ *Moultrie Geology, PO Box 433, Banyo, Brisbane, Australia \\ **Department of Geography, Ludwig-Maximilians-University, Munich, \\ Germany \\ ***Department of Geological Sciences, University of Canterbury, Christchurch, \\ New Zealand
}

Pre-print version (pre-refereeing)

\begin{abstract}
Melt rates on glaciers are strongly influenced by the presence of supraglacial debris, which can either enhance or reduce ablation relative to bare ice. Most recently, Franz Josef Glacier has entered into a phase of retreat and downwasting, with the increasing emergence of debris on the surface in the ablation zone. Typically at Franz Josef Glacier, melt has only been measured on bare ice, so in February 2012, a network of 11 ablation stakes was drilled into locations of varying debris thickness on the lower glacier. Mean ablation rates varied from 1.2 to $10.2 \mathrm{~cm} \mathrm{~d}^{-1}$, closely related to debris thickness. Concomitant observations of air temperature allowed the application of a degree-day approach to the calculation of melt rates, with air temperature proving a strong indicator of melt. Degree-day factors $(d f)$ ranged from 1.1 to $8.1 \mathrm{~mm} \mathrm{~d}^{-1}{ }^{\circ} \mathrm{C}^{-1}$ (mean of $4.4 \mathrm{~mm} \mathrm{~d}^{-1}{ }^{\circ} \mathrm{C}^{-1}$ ), comparable with rates reported in other studies. Mapping of the current debris cover revealed $0.7 \mathrm{~km}^{2}$ of the $4.9 \mathrm{~km}^{2}$ ablation zone was debris-covered, with thicknesses ranging from 1-50 mm. Based on measured debris thicknesses and $\mathrm{d} f$, ablation on debris-covered areas of the glacier is reduced by $41 \%$, equating to a $6 \%$ reduction in melt overall across the ablation zone.
\end{abstract}

\section{Introduction}

Glacier retreat in many regions is associated with the development of debris-covered ablation zones. Debris cover extent may range from completely debris-covered tongues (e.g. Miage Glacier, Italy; Smiraglia et al. 2000) to partly covered tongues (e.g. glaciers in Chenab basin, Himalaya; Shukla et al. 2009), and finally to discrete areas of fine dust and pebbles, as observed on many alpine glaciers (Mayer et al. 2011). That supraglacial debris cover modifies glacier behaviour is well known, based on several key small-scale field studies (e.g. $\emptyset$ strem 1959), complemented by theoretical studies based on heat flux calculations (e.g. Nakawo \& Young 1981). Empirical relationships between supraglacial debris thickness and ice-melt rates were initially established by $\emptyset$ strem (1959). Once a 'critical thickness' (debris thickness at which sub-debris ablation equals that under bare snow or ice) of debris is reached, a shielding effect dominates, which insulates the underlying ice, and slightly reduces melt rates (Østrem 1959). The critical thickness depends on physical properties of the debris and on meteorological conditions, with values reported in the literature varying between $2 \mathrm{~cm}$ 
(Mattson 2000) to 7-8 cm (Popovnin \& Rozova 2002). Under thicker debris covers, ablation rates progressively decline, a pattern that has been confirmed in several studies (e.g. Loomis 1970; Mattson et al. 1993; Nicholson \& Benn 2006). Hence, ablation under supraglacial debris is a balance between melt enhancement due to increased absorption of shortwave radiation, which dominates under thin debris-covers, and melt reduction through insulation from atmospheric heat and insolation, which dominates under thick covers (Nicholson \& Benn 2006).

In reality, the degree to which debris alters ablation at any given glacier, including the critical thickness at which ablation is retarded, is difficult to quantify (Scherler et al. 2011).

This is due to the typical highly heterogeneous nature of debris cover on glaciers, local climatic conditions (which may vary with latitude and altitude), and lithology (Reznichenko et al. 2010). While debris-covered glaciers are common in alpine environments such as the Himalaya, the Peruvian Andes, and the European Alps, there have been very few studies of the effect of debris cover on ice surface ablation in the New Zealand Southern Alps (Brook \& Paine 2012). Using a regional scale energy balance model, Anderson and Mackintosh (2012) found that in the central Southern Alps, debris covers reduce glacier mass balance sensitivity. Studies of the impact of debris cover on glacier ablation are important for three reasons. First, if mass balance data are unavailable, glacier advance and retreats are typically used as indicators of their response to climate change (Hooker \& Fitzharris 1999; Oerlemans 2005), even though terminus changes are not unambiguous indicators of glacier response to climate. Indeed, when supraglacial debris covers a significant proportion of the ablation zone, the glacier mass balance may become significantly less negative, influencing the behaviour of the terminus. This may, in turn, generate a terminal moraine that has only a partial climaterelated cause (Reznichenko et al. 2011). In New Zealand, evidence is emerging that some terminal moraine ridge formation in the past (e.g. the Late Glacial Waiho Loop moraine of Franz Josef Glacier) is linked to increased debris cover in ablation zones, rather than simple climatic-forcing (e.g. Shulmeister et al. 2009; Tovar et al. 2008). Second, of more immediate importance is the response of glaciers to future climate change since the current trend of glacier retreat has been widely accompanied by an increasing extent of debris cover on glacier tongues (Scherler et al. 2011). Long periods of negative mass balance increase the extent of debris cover on glaciers, and along with reduced ice velocities, accumulated debris over extended time periods leads to insulation of the ice surface and reduce local melt. Therefore, the role of the supraglacial debris cover control over ice melt is likely to become more significant with the prolonged negative glacier mass balances in the future. Third, debriscovered glaciers control the current and future availability of water. This may be of special relevance in regions like Central Asia, where mountains are surrounded by arid lowlands (Bolch et al. 2012). These areas are heavily dependent on glacier meltwater during the growing season for irrigation and drinking water. Indeed, in New Zealand, glacier-fed rivers in the central South Island contribute large portions of hydro-electricity generation, with improved lake-inflow forecasts required for enhanced management (Purdie \& Bardsley, 2010). Hence, an investigation into the effect of debris cover on ablation at one of New Zealand's most active and well-studied glaciers (Franz Josef Glacier) is timely. We herein present results of a field study of the effect of varying debris thickness on surface melt, and having mapped the debris cover and thickness, estimate the degree to which emerging debris cover on the lower part of Franz Josef Glacier reduces surface melt across the ablation zone. 


\section{Study Area}

Franz Josef Glacier is one of the best studied Southern Hemisphere glaciers, and is regarded as a key indicator of Southern Hemisphere climate change (Anderson et al. 2008). The $\sim 11$ $\mathrm{km}$ long glacier occupies $35 \mathrm{~km} 2$ on the western flank of the Southern Alps, is $\sim 6 \%$ of Southern Alps total ice volume (Fig. 1; Herman et al. 2011), and descends from a maximum elevation of $2900 \mathrm{~m}$ a.s.l. to a terminus at $\sim 280 \mathrm{~m}$ a.s.l (Alexander et al. 2011). The broad accumulation area consists of gently sloping snowfields, which converge into a heavily crevassed steep, narrow tongue, with the equilibrium line altitude (ELA) currently at 1860 $\mathrm{m}$ a.s.l. (Anderson et al. 2006). Precipitation increases from $\sim 7 \mathrm{~m} \mathrm{a}^{-1}$ at the terminus to $\sim 12$ $\mathrm{m} \mathrm{a}^{-1}$ at $600 \mathrm{~m}$ a.s.l., decreasing to $\sim 5 \mathrm{~m} \mathrm{a}^{-1}$ at the névé, while mean annual temperature varies from $\sim 9{ }^{\circ} \mathrm{C}$ at the terminus to approximately $-4{ }^{\circ} \mathrm{C}$ at the névé (Anderson et al. 2008). The corollary is a glacier system with both high accumulation and ablation rates, leading to velocities of $\sim 1000 \mathrm{~m} \mathrm{a}^{-1}$ (Herman et al. 2011), and a response time of 9-20 years (Oerlemans 1997). While Franz Josef Glacier has retreated substantially from its Little Ice Age maximum over the 20th century, it advanced $>1 \mathrm{~km}$ from the mid-1980s until the late 1990s, due to cool, wet conditions linked to the El Niño Southern Oscillation and Interdecadal Pacific Oscillation (Hooker \& Fitzharris 1999, Chinn et al. 2005). Over the last decade, the glacier has at first retreated, followed by an advance of $\sim 350 \mathrm{~m}$ since Mid-2005 until c. 2009, but it is now undergoing retreat and downwastage, leading to formation of features typical of debriscovered glaciers (Fig. 2). This has been accompanied by emergence of debris at the snout of the glacier, and development of a medial moraine (Fig. 3). The focus of this study is both the debris-covered snout and the medial moraine, previous ablation work at Franz Josef Glacier having solely focused on abundant clean ice surfaces (Marcus et al. 1985; Ishikawa et al. 1992; Anderson et al. 2008), when debris cover was negligible.

\section{Methods}

To determine the effect of a varying supraglacial debris thickness on ice melt, ablation was measured from 7 to the 16 February 2012 using a network of 11 light grey low-conductivity PVC ablation stakes. These were placed into hand-augered holes into the debris-covered ice through debris of varying thickness $(0$ to $45 \mathrm{~cm}$ ), which covered the entire variability of debris thicknesses observed. Stakes were installed on flat surfaces on areas of continuous, stable debris, with debris thickness measured at the beginning of the study period, and at each stake daily over the following 9 days. The altitude of the stake locations ranges from 360-480 $m$ a.s.l.. Disturbance of the debris cover was minimized as much as possible, and this included the use of a steel measuring tape that was extended down the side of each ablation pole to the debris-ice interface. For the thinnest debris covers, debris thickness was monitored and maintained using a trowel. For air temperature measurements, a Campbell HC2S3 temperature probe inside a radiation shield was attached to a Campbell CR1000 logger, logging at 5 minute intervals, installed on a stanchion $1.5 \mathrm{~m}$ above the debris-covered ice at the snout. Assuming an elevation gradient of $4.8^{\circ} \mathrm{C} / 1000 \mathrm{~m}$ (Anderson et al. 2006), this allowed the positive-degree-day (PDD) factor to be calculated for each stake. The PDD method assumes that the amount of ice melt during a period of study is directly proportional to the sum of the mean daily temperatures above $0^{\circ} \mathrm{C}$ over that period and enables comparison of ablation between different regions (Braithwaite 1995). This allows the calculation of the PDD factor ( $d f)$, which is derived from the sum of ablation divided by the sum of positive-degree-days, over the period of study. Despite simplifying complex energy 
fluxes, the PDD factor (in mm d-1 ${ }^{\circ} \mathrm{C}^{-1}$ ), has proven to be a very useful parameter where detailed energy balance measurements are lacking (Braithwaite 1995).

The relation between PDD and debris thickness can then be used to calculate melt for any given debris thickness and degree day sum. In order to estimate the influence of debris cover on ice melt across the ablation zone, thickness and spatial distribution of debris was mapped in the field using a global positioning system (GPS). Mapped debris thickness data were then added, in ArcGIS, as shape files onto a georegistered aerial photograph $(0.4 \mathrm{~m}$ ground resolution) of Franz Josef Glacier (Fig. 1) acquired by New Zealand Aerial Mapping in February 2011 (Survey Number: 50850X, Run and Frame: 16/1885). Visual interpretation of the orthophoto in combination with numerous field observations allowed subdivision of the debris-covered areas of the glacier into 79 polygons of homogeneous appearance and known thickness (Fig. 4). For each polygon, the relative deviations from clean ice ablation was calculated. For this purpose, the best line fit of an exponential relation between PDD and debris thickness was used. By considering the areas of the polygons, the relative impact of supraglacial debris on surface melt could be estimated.

\section{Results}

Cumulative ablation for each of the 11 stakes is reported in Fig. 5 along with temperature, which showed typical diurnal variability of between $\sim 10$ and $\sim 18^{\circ} \mathrm{C}$. At several stakes readings were taken twice daily, and the cumulative ablation curves (Fig. 5) indicate that melt progressed during night time too, confirming the effect of the positive air temperatures that are quite typical for maritime mid-latitudinal glaciers (Alexander et al. 2011. Daily melt rates varied from 1.2 to $10.1 \mathrm{~cm} \mathrm{~d}^{-1}$ under debris cover of $43 \mathrm{~cm}$ and $0 \mathrm{~cm}$ thickness, respectively, with a mean of $5.3 \mathrm{~cm} \mathrm{~d}^{-1}$ (Fig. 5, Table 1). The relationship between debris cover and melt rate is shown in Fig. 6A, with the relationship of $\varnothing$ strem (1959) superimposed on the plot. As can be seen from the graph, ablation decreases asymptotically with increasing debris thickness, and following the exponential regression model reported on the graph, would be close to zero with a debris thickness of $\sim 85 \mathrm{~cm}$. Nevertheless, there is no evidence for increased ablation relative to clean ice under a very fine debris cover. As accurate measurements over very thin debris layers are difficult to conduct, $\varnothing$ strem (1959) has also dotted his graph in this thickness range, rather than reporting observed values. Indeed, the average ablation rate for bare ice $\left(10.1 \mathrm{~cm} \mathrm{~d}^{-1}\right)$ was not exceeded at any of our observed locations, which agrees with the findings of Mihalcea et al. (2008). This may reflect that bare ice locations were not in fact perfectly clean, but included dust which would lower albedo and increase absorption of solar energy. To allow direct comparison with other studies, a degreeday-factor, $d f$, was calculated

from air temperature, which can be extrapolated to all of the stakes due to rather constant lapse rates. This temperature index method based on mean air temperature is beneficial because it is strongly connected to the most important energy fluxes in alpine environments, solar radiation and sensible heat flux (Ohmura 2001). The air temperature record allowed calculation of $\mathrm{d} f$ for all the stakes in this study, with $\mathrm{d} f$ varying from $1.1 \mathrm{~mm} \mathrm{~d}-1{ }^{\circ} \mathrm{C}^{-1}$ under 43 $\mathrm{cm}$ of debris to a maximum of $8.1 \mathrm{~mm} \mathrm{~d}^{-1}{ }^{\circ} \mathrm{C}^{-1}$ under bare ice (Fig. 6B), with a mean value of $4.4 \mathrm{~mm} \mathrm{~d}-1^{\circ} \mathrm{C}^{-1}$.

The close fit $\left(r^{2}=0.86\right)$ of the exponential regression $(y=0.595-0.051 x)$ to the debris thickness and degree-day melt-rates indicates that it should be possible to estimate ablation rates under supraglacial debris, if temperature and debris thickness are known. This was 
undertaken for the ablation zone using the high resolution aerial photograph in Fig. 1 and field mapping of debris thicknesses (Fig. 4). Results show that $0.7 \mathrm{~km} 2$ of the $4.9 \mathrm{~km} 2$ ablation zone is currently debris-covered, with thicknesses ranging from $1 \mathrm{~mm}$ to $50 \mathrm{~mm}$. Based on the measured debris thicknesses and $\mathrm{d} f$, within the debris covered area of the glacier, ablation is reduced by $41 \%$ at the present time. Considering the whole ablation area, the current debris cover reduces ice melt by $6 \%$.

\section{Discussion}

Ablation at Franz Josef Glacier appears to follow the general trends outlined in previous studies globally, with ablation being reduced under thicker debris layers (e.g. Østrem 1959; Loomis 1970; Brock et al. 2007). At the same altitude, an increase in debris cover from 2.5 $\mathrm{cm}$ to $10 \mathrm{~cm}$ is accompanied by a $32 \%$ decrease in melt (Fig. 6), showing that a small change in debris thickness causes a marked change in energy available for ice melt. Nevertheless, although our study provides a good general match to the general form of the $\varnothing$ strem (1959) curve, showing an asymptotic decline in melt with increasing debris thickness, it does not mimic the 'rising limb', as found in many previous studies (e.g. Tangborn \& Rana 2000). Instead, our results show falling melt rates with increasing debris thickness, even for miniscule debris layers, consistent with Mihalcea et al. (2006) and Brock et al. (2007). This may reflect that bare ice locations where not absolutely clean, and that albedo was lowered by the presence of small amounts of dust and cryoconite, increasing absorption of solar energy. While the degree day factor ( $d f$ for 'bare' ice for the present study of $8.1 \mathrm{~mm} \mathrm{~d}-1{ }^{\circ} \mathrm{C}^{-1}$ is close to the upper end of the range in $\mathrm{d} f\left(5.5\right.$ to7.7 $\left.\mathrm{mm} \mathrm{d}^{-1}{ }^{\circ} \mathrm{C}^{-1}\right)$ reported for a selection of glaciers globally by Braithwaite (1995), it is higher than the $\mathrm{d} f$ of $5.1 \mathrm{~mm} \mathrm{~d}-1{ }^{\circ} \mathrm{C}^{-1}$ reported for nearby Fox Glacier by Brook and Paine (2012). The range in $\mathrm{d} f$ in this study $\left(1.1\right.$ to $\left.8.1 \mathrm{~mm} \mathrm{~d}-1^{\circ} \mathrm{C}^{-1}\right)$ is close to, and in some cases overlaps, ranges of $d f$ values reported from a host of other debris-covered glaciers from different continents. Indeed, $\mathrm{d} f$ values of 1.6 to $10.6 \mathrm{~mm} \mathrm{~d}^{-1}{ }^{\circ} \mathrm{C}^{-1}$ for 24K Glacier, southeast Tibet were reported by Wei et al. (2010), Hagg et al. (2008) reported df of 4.1 to $9.3 \mathrm{~mm} \mathrm{~d}-1{ }^{\circ} \mathrm{C}^{-1}$ for Inylchek Glacier, central Tian Shan, while Brook and Paine (2012) reported a range in $\mathrm{d} f$ of 1.2 to $5.9 \mathrm{~mm} \mathrm{~d}^{-1}{ }^{\circ} \mathrm{C}^{-1}$ at Fox Glacier. To allow a closer evaluation with other studies, comparisons of $d f$ for debris thicknesses of $10 \mathrm{~cm}$ can be made, with $\mathrm{d} f$ values of $15.6 \mathrm{~mm} \mathrm{~d}^{-1}{ }^{\circ} \mathrm{C}^{-1}, 14.0 \mathrm{~mm} \mathrm{~d}^{-1}{ }^{\circ} \mathrm{C}^{-1}, 5.5 \mathrm{~mm} \mathrm{~d}^{-1}{ }^{\circ} \mathrm{C}-13.5 \mathrm{~mm} \mathrm{~d}^{-1}{ }^{\circ} \mathrm{C}^{-1}$ and , reported for the Himalayan AX010, Khumbu, Rakhiot and Lirung Glaciers, respectively (Kayastha et al. 2000), and $3.8 \mathrm{~mm} \mathrm{~d}^{-1}{ }^{\circ} \mathrm{C}^{-1}$ and $3.5 \mathrm{~mm} \mathrm{~d}^{-1}{ }^{\circ} \mathrm{C}^{-1}$, reported respectively, for Fox and Inylchek Glaciers (Hagg et al. 2008; Brook \& Paine 2012).

The subtle variations in $\mathrm{d} f$ between these studies is intriguing, and is mainly due to geographical conditions (elevation, latitude, aspect, shading), local geology and debris layer porosity and permeability (controlling debris surface albedo and thermal resistance), and meteorological conditions (cloudiness and rainfall). Indeed, ice ablation is controlled by the amount of energy supplied to ice (Cuffy \& Paterson 2010), which is influenced by the interplay between the surface energy balance and heat transfer processes through the debris layer. This determines the amount of energy reaching the ice-debris interface. Marcus et al. (1985) highlighted the possible effects of rainfall events on ablation, arguing that surface runoff due to rainfall may intercept and advect a substantial portion of incoming energy fluxes, with percolating rainfall advecting heat from the warm debris to the ice (e.g. Reznichenko et al. 2010). Although our survey period did include days with precipitation, our results indicate that temperature alone, as defined by $\mathrm{d} f$, is a strong predictor of sub-debris 
melt, indicating heat flux supplied by rain has little effect on the energy balance at the ice-debris interface, unlike on clean ice surfaces (Ishikawa et al. 1992) at Franz Josef Glacier.

This is in accord with conclusions from previous studies in the Italian Alps (Brock et al. 2010), the Himalaya (Takeuchi et al. 2000; Kayastha et al. 2000), the Karakorum (Mattson \& Gardner 1991) and Svalbard (Nicholson \& Benn 2006). Moreover, statistical modelling by Reid and Brock (2010) on the effect of precipitation on melt beneath a debris layer found that the heat flux from precipitation could be omitted without significant loss in model performance.

A further control on $\mathrm{d} f$ accounting for differences between sites may be diurnal radiation cycles. Laboratory data from Reznichenko et al. (2010) indicates that diurnal cyclicity is crucial to insulation under debris, with the relative amplitudes and durations of the heating and cooling parts of the radiation cycle determining the degree of insulation effect of the debris cover. Reznichenko et al. (2010) found that a given depth of debris has a particular thermal inertia, and that the duration and intensity of the radiation cycles, relative to this inertia, determine the delivery of energy to the underlying ice and thus the melt rate. Decreasing $\mathrm{d} f$ with increasing latitude is explained by the decreasing amplitude of the diurnal cycle with increasing latitude, and the corresponding decrease of average temperatures (Barry 2008). Also, with increasing altitude the diurnal temperature amplitude increases, due to enhanced outward radiation (Oerlemans 2001) and lower temperatures at night. A further factor influencing $d f$ between sites is the degree of continentality of the climate. Continental climates are characterized by less cloudiness and consequently greater shortwave radiation in the glacier surface heat budget than maritime glaciers, such as Franz Josef Glacier (Oerlemans 2001). Under continental conditions, low annual precipitations should lead to drier debris covers which have a higher thermal resistance. Hence, although temperature itself is a strong predictor of ice melt at Franz Josef Glacier, a range of synoptic conditions can act to modify the insulating effects of debris covers.

Our study confirms that at Franz Josef Glacier, debris cover significantly reduces ablation rates, with ablation beneath the debris-covered part of the ablation zone reduced by $41 \%$. The implication of this is that the behaviour of the glacier will to some extent become less determined by the climate with increased debris cover (e.g. Reznichenko et al. 2010). Hence, the extensive area of debris-covered ice at the terminus of Franz Josef Glacier is likely to persist for some decades, gradually lowering over time as downwastage proceeds. A similar phenomena could be observed at nearby Fox Glacier, although that dead-ice complex was buried by a rather thick debris-flow deposit and did exist for several decades before finally melting completely during the past 10 years. This study has implications for two recent modelling studies of Franz Josef Glacier (e.g. Vacco et al. 2010; Shulmeister et al. 2009). The models predict that the effect of a late glacial rock avalanche onto the surface of Franz Josef Glacier would have led to an advance independent of any climate-forcing, followed by stagnation of the debris-covered advanced ice tongue. Both models propose that if a rock avalanche caused an advance of Franz Josef Glacier leading to formation of the Waiho Loop terminal moraine, a significant carpet of 'hummocky' moraine would have formed behind the rather well-defined moraine ridge of the Waiho Loop. However, such landforms are not visible on today's surface. Using the relationship between debris cover and ablation in Fig. 6B, under a debris thickness of $5 \mathrm{~m}$ (as suggested by Shulmeister et al. 2009), ablation is negligible, theoretically with a $\mathrm{d} f$ of $5.02-12 \mathrm{~mm} \mathrm{~d}^{-1}{ }^{\circ} \mathrm{C}^{-1}$. Given the annual positive degree-day values typically recorded at the NIWA Franz Josef Glacier automatic weather 
station $\left(\sim 3600^{\circ} \mathrm{C} \mathrm{yr}^{-1}\right)$, an extended Franz Josef Glacier tongue under a debris cover of $5 \mathrm{~m}$ would exist for many centuries, presumably forming substantial hummocky moraines as downwastage proceeded (e.g. Shulmeister et al. 2009), since covered by aggradational fans. Nevertheless, despite the attractiveness of applying our measured ablation rates to their simple models, the major continuing uncertainty is the late glacial climate conditions and the dynamic status of Franz Josef Glacier at the time of such massive rock avalanche events.

\section{Conclusion}

A dataset of ablation measurements on debris-covered areas of Franz Josef Glacier has been presented. At the ablation stakes, each under debris of different thickness, mean melt rates varied between 12 and $101 \mathrm{~mm} \mathrm{~d}^{-1}$. The decrease in melt with increasing debris thickness followed the hyperbolic relationship identified in other studies, although the 'rising limb' as proposed by $\emptyset$ strem (1959) was not identified. Indeed, a critical thickness (defined as the thickness at which the underlying ice ablation equals that of adjacent bare ice, with increases in thickness causing the debris to have an insulation effect) that has been reported at a number of glaciers around the world, was not identified. As soon as debris was present on the ice surface, melt was reduced. Temperature measurements from an automatic weather station on the glacier surface allowed the application of a positive degree-day approach to calculate ablation, and allow comparison with other studies globally. Air temperature alone proved to be a strong predictor of ice melt, and degree-day factors ( $d f$ ) ranged from 1.1 to $8.1 \mathrm{~mm} \mathrm{~d}^{-1}$ ${ }^{\circ} \mathrm{C}^{-1}$, with a mean value of $4.4 \mathrm{~mm} \mathrm{~d}^{-1}{ }^{\circ} \mathrm{C}^{-1}$.

Other factors that might influence ablation include precipitation, in particular its effect on heat advection through the debris layer, and diurnal cyclicity of radiation cycles, the effects of which could be measured in future with thermistors placed in situ at varying depths within the debris layer. Due to the strong relationship between debris thickness and ice melt, remote sensing data could be used to delineate the spatial distribution of debris thicknesses across broad areas, and its likely effect on ablation reduction. Given the critical role of paleoclimatology in understanding future glacier responses to climate change, the present study has shown that improved appreciation of the effects of supraglacial debris on ablation at temperate maritime glaciers, is critical to understanding moraine formation in such settings.

\section{Acknowledgements}

We thank the Department of Conservation for allowing fieldwork on Franz Josef Glacier and Massey University for funding Wilfried Hagg's visit and research costs. The work was undertaken while Martin Brook was a senior lecturer in Earth Science, within the Institute of Natural Resources, Massey University. New Zealand Aerial Mapping is thanked for prompt provision of an excellent aerial photo.

\section{References}

Alexander DJ, Davies TR, Shulmeister J 2011. A steady-state mass-balance model for the Franz Josef Glacier, New Zealand: testing and application Geografiska Annaler 93A(1): 41-54.

Anderson B, Lawson W, Owens I, Goodsell B 2006. Past and future mass balance of 'Ka Roimata o Hine Hukatere' Franz Josef Glacier, New Zealand. Journal of Glaciology 
52(179): 597-607.

Anderson B, Lawson W, Owens I 2008. Response of Franz Josef Glacier Ka Roimata o Hine Hukatere to climate change. Global and Planetary Change 63: 23-30.

Anderson, BM., Mackintosh AN 2012. Controls on mass balance sensitivity of maritime glaciers in the Southern Alps, New Zealand: The role of debris-cover, Journal of Geophysical Research 117: F01003, doi:10.1029/2011JF002064.

Barry RG, 2008. Mountain weather and climate. Cambridge, Cambridge University Press. $506 p$.

Bolch T, Kulkarni A, Kääb A, Huggel C, Paul F, Cogley JG, Frey H, Kargel JS, Fujita K, Scheel M, Bajracharya S, Stoffel M (2012): The state and fate of Himalayan glaciers. Science 336, $310-314$.

Braithwaite RJ 1995. Positive degree-day factors for ablation on the Greenland Ice Sheet studied by energy-balance modelling. Journal of Glaciology 41(137): 153-160.

Brock B, Rivera A, Casassa G, Bown F, Acuna C 2007. The surface energy balance of an active ice-covered volcano: Villarrica Volcano, southern Chile. Annals of Glaciology 45: 104-114.

Brock BW, Mihalcea C, Kirkbride MP, Diolaiuti G, Cutler MEJ, Smiraglia C 2010. Meteorology and surface energy fluxes in the 2005-2007 ablation seasons at the Miage debris-covered glacier, Mont Blanc Massif, Italian Alps. Journal of Geophysical Research-Atmospheres 115: Article Number: D09106 DOI: 10.1029/2009JD013224.

Brook MS, Paine S 2012. Ablation of ice-cored moraine in a humid maritime climate: Fox Glacier, New Zealand. Geografiska Annaler 94A: doi:10.1111/j.1468-

0459.2011.00442.x

Chinn TJH, Winkler S, Salinger MJ, Haakensen N 2005: Recent glacier advances in Norway and New Zealand - a comparison for their glaciological and meteorological causes. Geografiska Annaler 87 A: 141 - 157.

Cuffey W, Paterson WSB 2010: The physics of glaciers. Burlington, ButterworthHeinemann $693 \mathrm{pp}$.

Eyles N, Rogerson RJ 1978: A framework for the investigation of medial moraines formation: Austerdalsbreen, Norway, and Berendon Glacier, British Columbia, Canada. Journal of Glaciology 20: 99-113.

Hagg W, Mayer C, Lambrecht A, Helm A 2008. Sub-debris melt rates on southern Inylchek Glacier, central Tian Shan. Geografiska Annaler 90A(1): 55-63. 
Herman F, Anderson B, Leprince S 2011. Mountain glacier velocity variation during a retreat/advance cycle quantified using sub-pixel analysis of ASTER images. Journal of Glaciology 57(202): 197-207.

Hooker BL, Fitzharris BB 1999. The correlation between climatic parameters and the retreat and advance of Franz Josef Glacier, New Zealand. Global and Planetary Change 22(14): 39-48.

Ishikawa N, Owens IF, Sturman AP 1992. Heat balance characteristics during fine periods on the lower parts of the Franz Josef Glacier, South Westland, New Zealand. International Journal of Climatology 12: 397-410.

Kayastha RB, Takeuchi Y, Nakawo M, Ageta Y 2000. Practical prediction of ice melting beneath various thickness of debris cover on Khumbu Glacier, Nepal, using a positive degree-day factor. IAHS Publication 264: 71-81.

Loomis SR 1970. Morphology and structure of an ice-cored medial moraine, Kaskawulsh Glacier, Yukon. In: Loomis SR, Dozier J, Ewing KJ eds. Studies of Morphology and Stream Action on Ablating Ice. Research Paper No. 57, Arctic Institute of North America Pp. 1-56.

Marcus MG, Moore RD, Owens IF 1985. Short-term estimates of surface-energy transfers and ablation on the lower glacier, Franz Josef Glacier, South Westland, New Zealand. New Zealand Journal of Geology and Geophysics 28(3): 559-567.

Mattson LE, Gardner JS 1991. Energy exchanges and ablation rates on the debris covered Rakhiot Glacier, Pakistan. Zeitschrift für Gletscherkunde und Glazialgeologie 25(1): 17-32.

Mattson LE, Gardner JS, Young GJ 1993. Ablation on debris covered glaciers: an example from the Rakhiot Glacier, Panjab, Himalaya. IAHS Publication 218: 289-296.

Mayer C, Lambrecht A, Hagg W, Narozhny Y 2011. Glacial debris cover and melt water production for glaciers in the Altay, Russia. The Cryosphere Discussions 5: 401-430.

Mihalcea C, Brock BW, Diolaiuti G, D'Agata C, Citterio M, Kirkbride MP, Cutler MEJ, Smiraglia C 2008. Using ASTER satellite and ground-based surface temperature measurements to derive supraglacial debris cover and thickness patterns on Miage Glacier (Mont Blanc Massif, Italy). Cold Regions Science and Technology 52: 341-354.

Nakawo M, Young GJ 1981. Field experiments to determine the effect of a debris layer on ablation of glacier ice. Annals of Glaciology 2: 85-91.

Nicholson L, Benn DI 2006. Calculating ice melt beneath a debris layer using meteorological data. Journal of Glaciology 52(178): 463-470. 
Oerlemans J 1997. Climate sensitivity of Franz Josef Glacier, New Zealand, as revealed by numerical modelling. Arctic and Alpine Research 29(2): 233-239.

Oerlemans J 2001. Glaciers and climate change. Rotterdam, Balkema. 148p.

Oerlemans J 2005. Extracting a climate signal from 169 glacier records. Science 308: 675-677.

Ohmura A 2001. Physical basis for the temperature-based melt index method. Journal of Applied Meteorology 40: 753-761.

Ohmura A, Kaser P, Funk M 1992. Climate at the equilibrium line of glaciers. Journal of Glaciology 38(130): 397-411.

$\varnothing$ strem G 1959. Ice melting under a thin layer of moraine and the existence of ice cores in moraine ridges. Geografiska Annaler 41: 228-230.

Popovnin VV, Rozova AV 2002. Influence of sub-debris thawing on ablation and runoff of the Djankuat Glacier in the Caucasus. Nordic Hydrology 33: 79-94.

Purdie JM, Bardsley WE 2010. Seasonal prediction of lake inflows and rainfall in a hydroelectricity catchment, Waitaki river, New Zealand. International Journal of Climatology 30(3): 372-389.

Reid TD, Brock BW 2010. An energy-balance model for debris-covered glaciers including heat conduction through the debris layer. Journal of Glaciology 56(199): 903-916.

Reznichenko N, Davies T, Shulmeister J, McSaveney M 2010. Effects of debris on icesurface melting rates: an experimental study. Journal of Glaciology 56(197): 384-394.

Reznichenko NV, Davies TRH, Alexander DJ 2011. Effects of rock avalanches on glacier behaviour and moraine formation. Geomorphology 132(3-4): 327-338.

Scherler D, Bookhagen B, Strecker MR 2011. Spatially variable response of Himalayan glaciers to climate change affected by debris cover. Nature Geoscience 4(3): 156-159.

Shulka A, Gupta RP, Arora MK (2009): Estimation of debris cover and its temporal variation using optical satellite sensor data: a case study in Chenab basin, Himalaya. Journal of Glaciology 55 (191), $444-452$.

Shulmeister J, Davies TR, Evans DJA, Hyatt OM, Tovar DS 2009. Catastrophic landslides, glacier behaviour and moraine formation - A view from an active plate margin. Quaternary Science Reviews 28(11-12): 1085-1096.

Smiraglia C, Diolaiuti G, Casati D, Kirkbride MP 2000. Recent areal and altimetric variations of Miage Glacier (Monte Bianco massif, Italian Alps). IAHS Publication 264: 227-233. Tangborn W, Rana B 2000. Mass balance and runoff of the partially debris-covered Langtang 
Glacier, Nepal. IAHS Publication 264: 99-108.

Tovar DS, Shulmeister J, Davies TR 2008. Evidence for a landslide origin of New Zealand's Waiho Loop moraine. Nature Geoscience 1(8): 524-526.

Vacco DA, Alley RB, Pollard D 2010. Glacial advance and stagnation caused by rock avalanches. Earth and Planetary Science Letters 294(1-2): 123-130.

Yang W, Yao TD, Xu BQ, Zhou H 2010. Influence of supraglacial debris on summer ablation and mass balance in the $24 \mathrm{~K}$ Glacier, southeast Tibetan Plateau. Geografiska Annaler 92A: 353-360. 




Figure 1. Location map of Franz Josef Glacier, including debris covered zones at the terminus and the medial moraine. Numbers refer to ablation stakes in Table 1. 

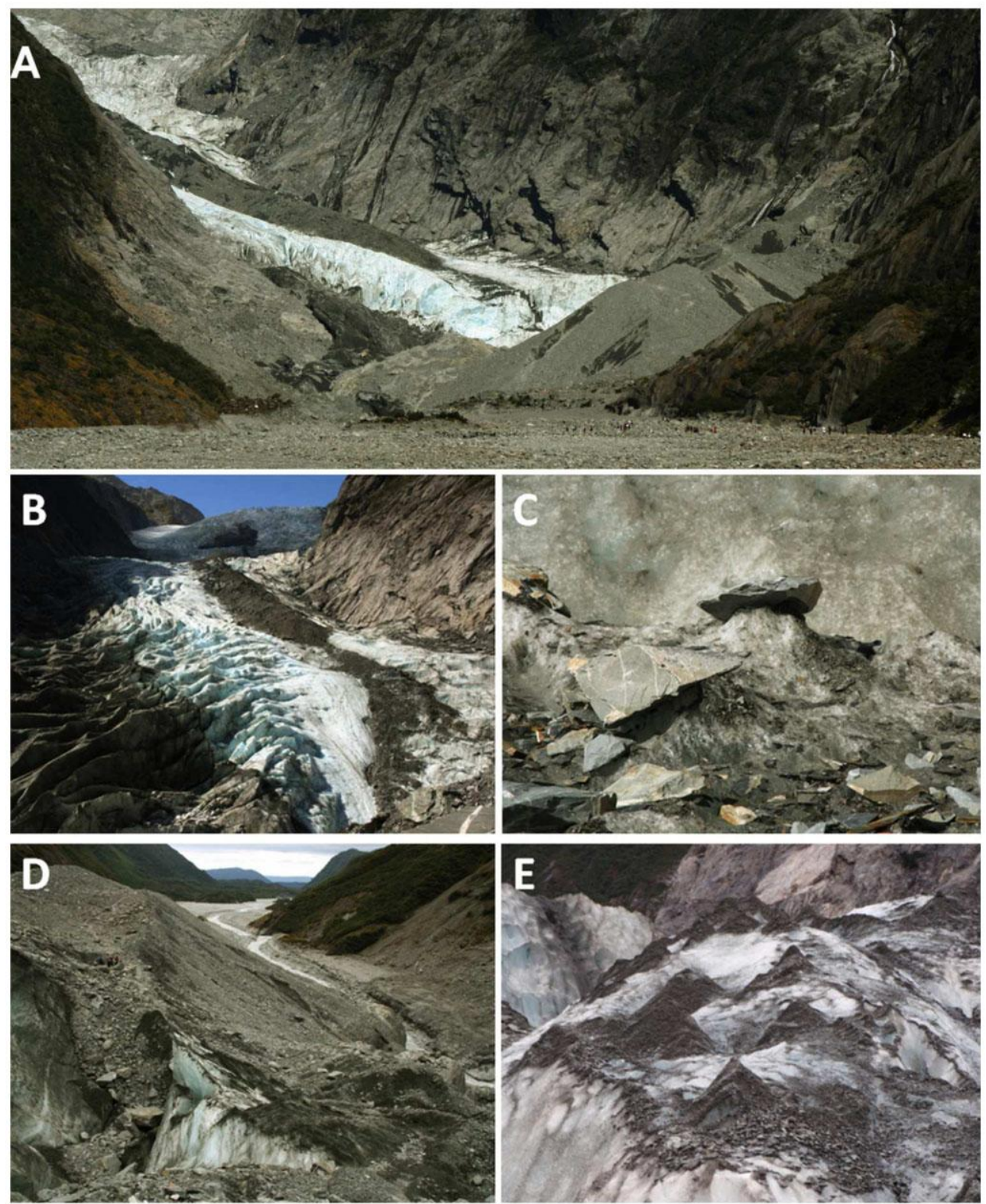

Figure 2. Debris cover and landforms on the lower Franz Josef Glacier: (A) Differential ablation at the terminus of Franz Josef Glacier, as shown by the contrast in surface elevations of both the debris-covered terminus and medial moraine, compared with bare ice surfaces; (B) medial moraine (AD-2 type sensu Eyles \& Rogerson 1978) formed by emergence of englacial debris that has been entrained within the glacier above the equilibrium line altitude (ELA); (C) 'glacier table' formed by insolation shielding of ice pedestal; (D) the debriscovered terminus, with clean ice surfaces visible beneath the $<0.5 \mathrm{~m}$ thick debris; (E) ablation cones forming at the point of emergence of englacial debris at the upper end of the medial moraine under very thin debris $(\sim 2 \mathrm{~cm})$. 


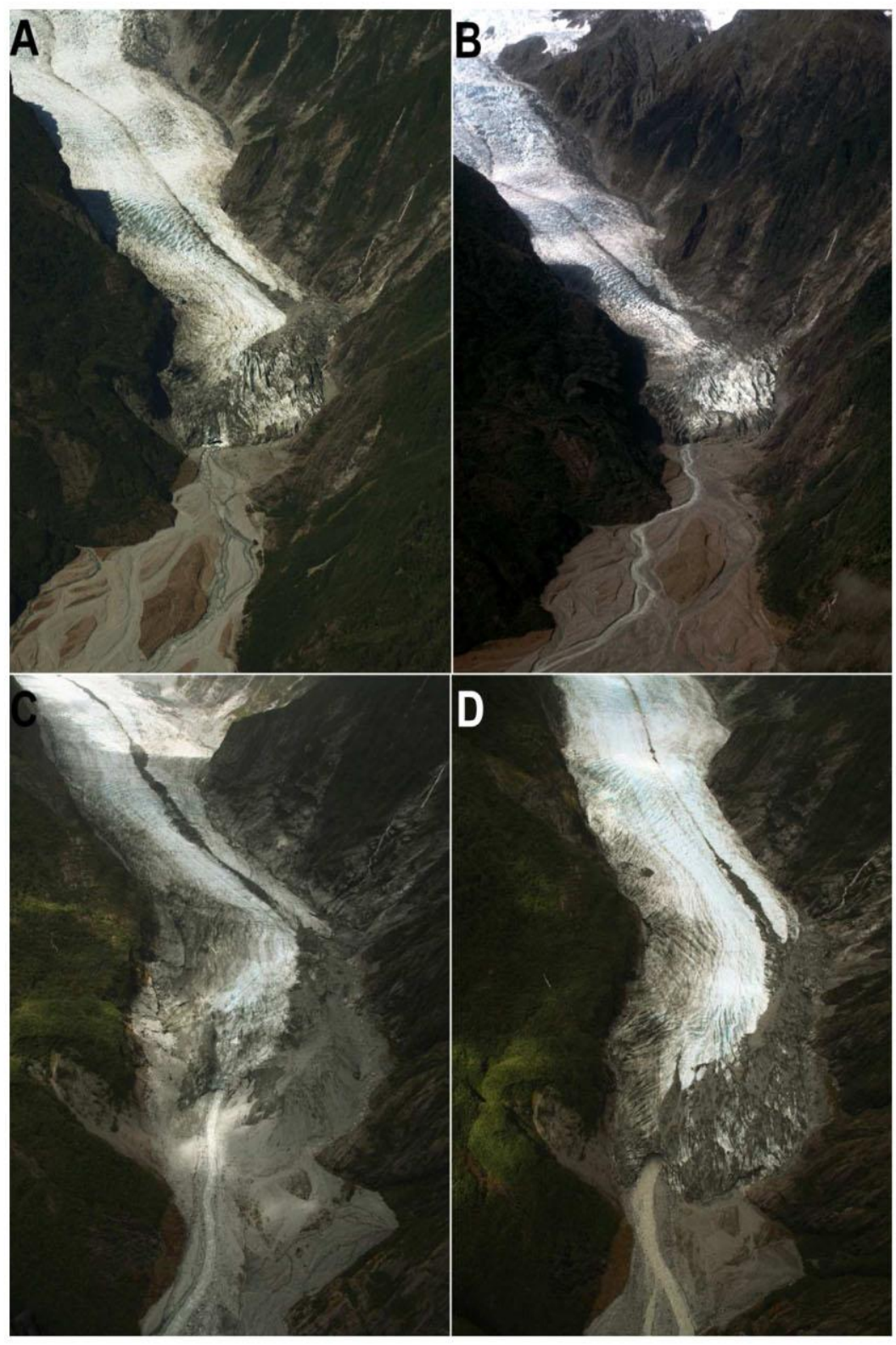

Figure 3. Changes of the debris cover on the lower glacier tongue of Franz Josef Glacier as seen on oblique aerial photographs (A: 03.03.2006; B: 27.03.2007; C: 28.0.2008; D:

08.12.2010). 


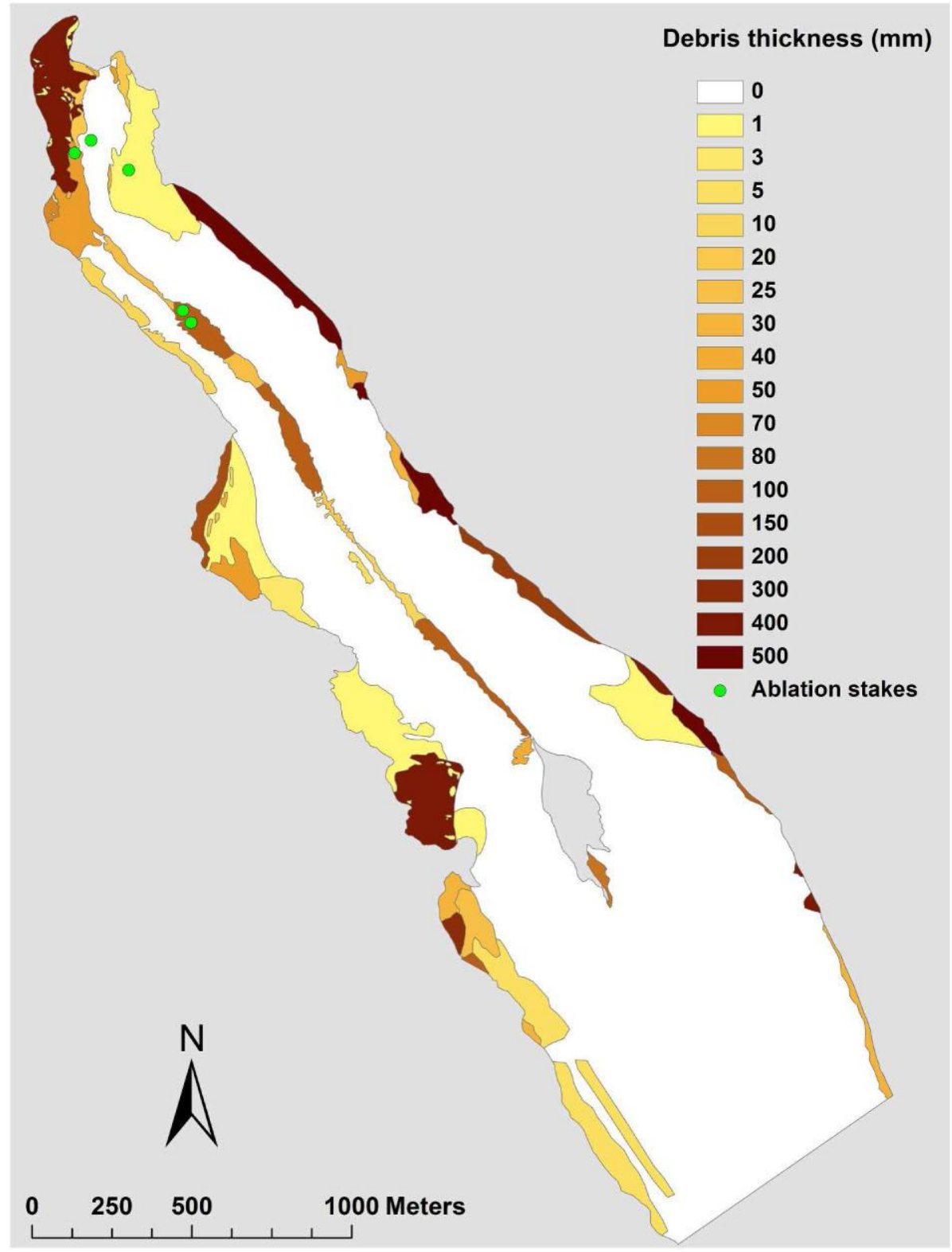

Figure 4. Map of debris thickness on the lower Franz Josef Glacier, used to calculate percent reduction in ablation, relative to clean ice conditions. 


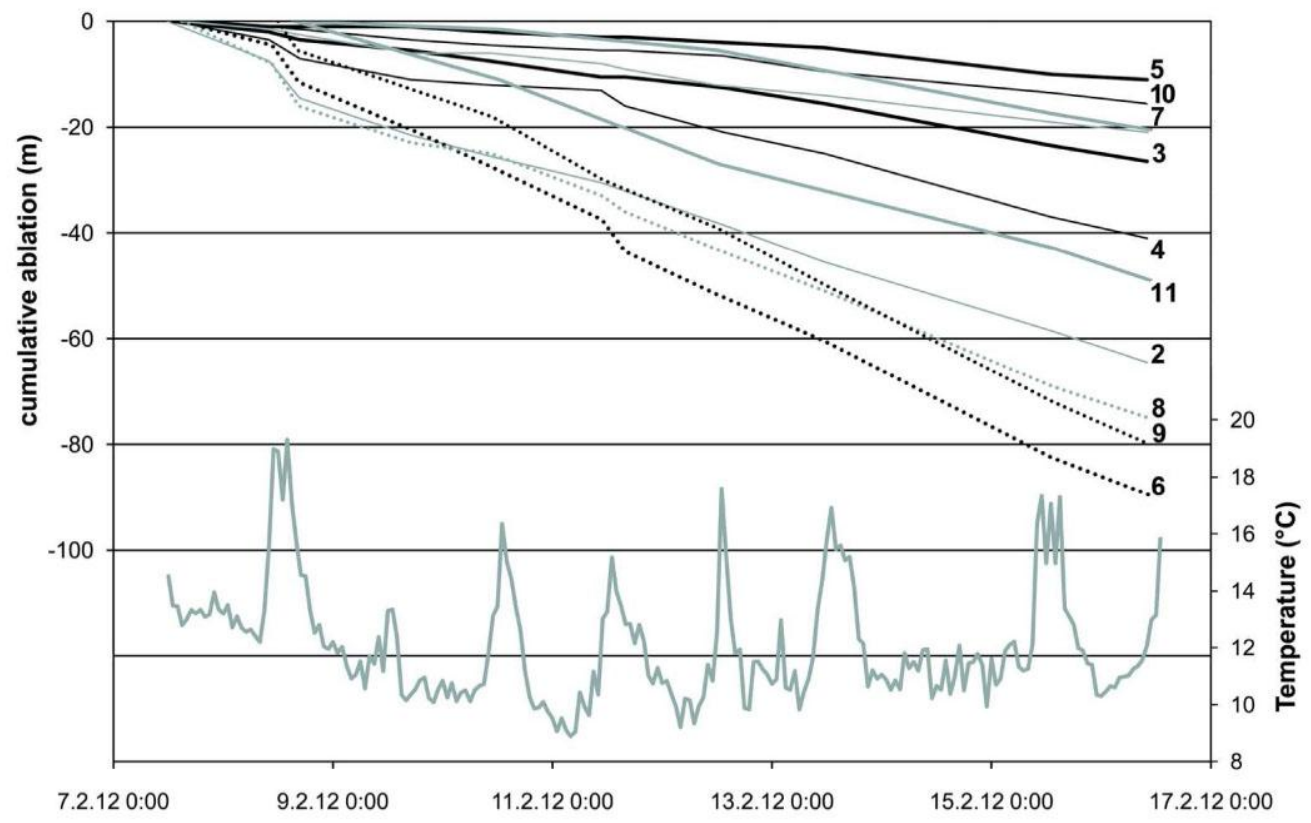

Figure 5. Upper graph shows the full record of daily ablation measurements at each stake. The lower graph shows temperature logged at 5 minute intervals at an automatic weather station located on the debris-covered ice at the terminus. 

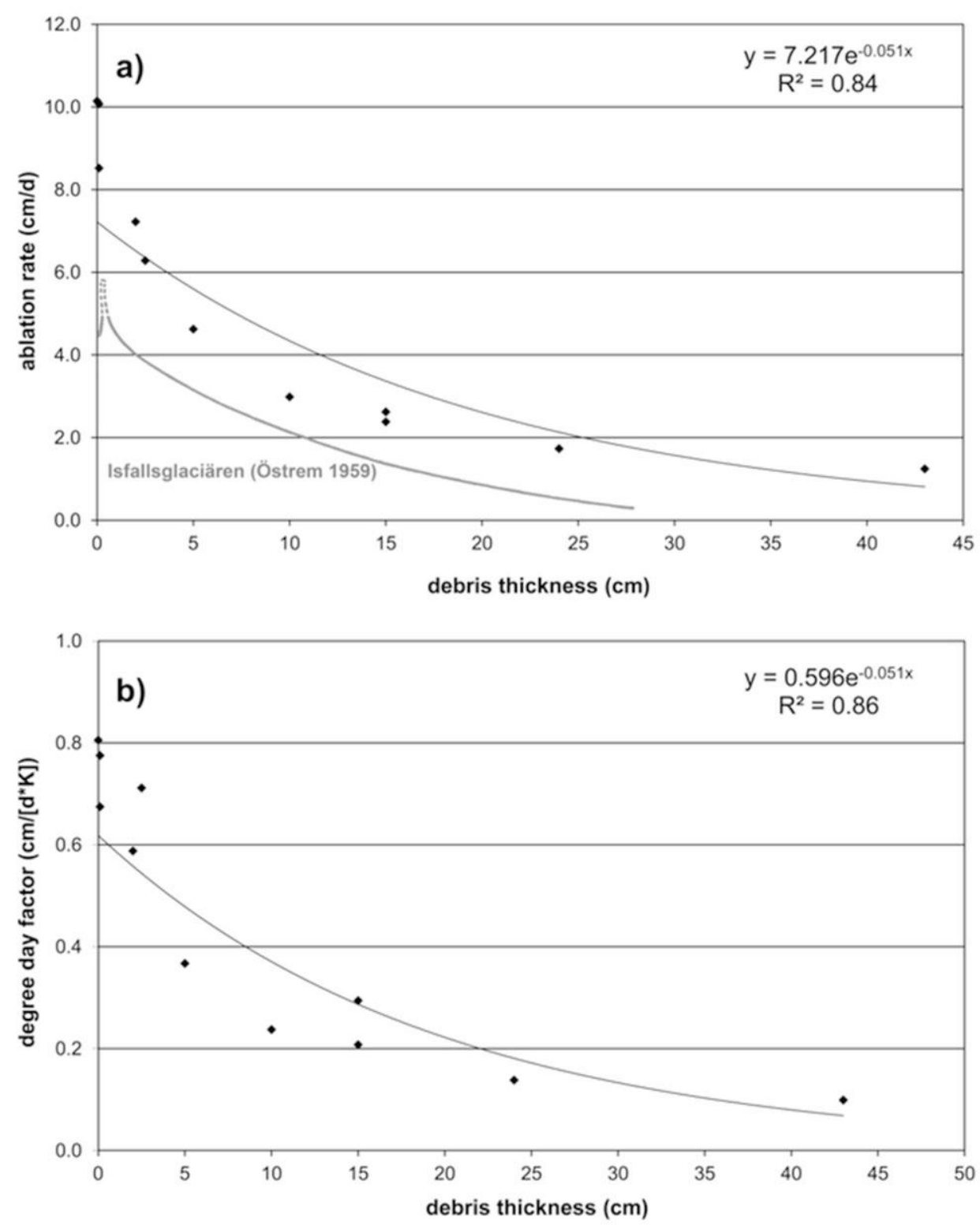

Figure 6. (A) Relationship between ablation and debris cover as measured from the ablation stakes; (B) relationship between ablation rate degree-day factor (df). 
Table 1

\begin{tabular}{lccccc}
\hline $\begin{array}{l}\text { Stake } \\
\text { number }\end{array}$ & $\begin{array}{c}\text { Debris } \\
\text { thickness }(\mathbf{c m})\end{array}$ & $\begin{array}{c}\text { Total } \\
\text { ablation }(\mathbf{c m})\end{array}$ & $\begin{array}{c}\text { Ablation rate } \\
\left(\mathbf{c m ~ d}^{-\mathbf{1}}\right)\end{array}$ & $\begin{array}{c}\text { Mean temp. } \\
\left({ }^{\circ} \mathbf{C}\right)\end{array}$ & $\begin{array}{c}\mathbf{d}_{f} \\
\left(\mathbf{m m ~ d}^{-\mathbf{1}}{ }^{\circ} \mathbf{C}^{-\mathbf{1}}\right)\end{array}$ \\
\hline 1 & 24 & 155.0 & 17.3 & 12.5 & 1.4 \\
2 & 2 & 645.0 & 72.2 & 12.3 & 5.9 \\
3 & 10 & 265.0 & 29.8 & 12.6 & 2.4 \\
4 & 5 & 410.0 & 46.3 & 12.6 & 3.7 \\
5 & 43 & 110.0 & 12.4 & 12.6 & 1.0 \\
6 & 0 & 895.0 & 101.4 & 12.6 & 8.1 \\
7 & 15 & 210.0 & 23.8 & 12.6 & 2.1 \\
8 & 0.1 & 750.0 & 85.2 & 12.6 & 6.7 \\
9 & 0.1 & 800.0 & 100.7 & 13.0 & 7.8 \\
10 & 15 & 205.0 & 26.2 & 8.9 & 2.9 \\
11 & 2.5 & 490.0 & 62.8 & 8.8 & 7.1 \\
\hline
\end{tabular}

